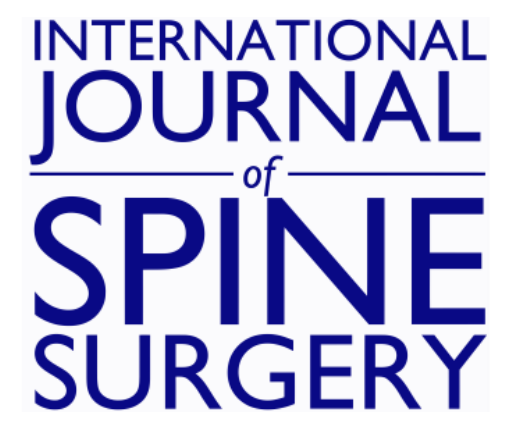

\title{
The Influence of Lordotic cages on creating Sagittal Balance in the CMIS treatment of Adult Spinal Deformity
}

Neel Anand, Ryan B. Cohen, Jason Cohen, Babak Kahndehroo, Sheila Kahwaty and Eli Baron

Int J Spine Surg 2017, 11 (3)

doi: https://doi.org/10.14444/4023

http://ijssurgery.com/content/11/3/23

This information is current as of April 25, 2023.

Email Alerts Receive free email-alerts when new articles cite this article. Sign up at:

http://ijssurgery.com/alerts

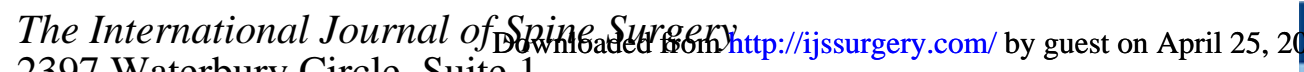
2397 Waterbury Circle, Suite 1,

Aurora, IL 60504, Phone: +1-630-375-1432 


\section{The Influence of Lordotic cages on creating Sagittal Balance in the CMIS treatment of Adult Spinal Deformity}

Neel Anand, MD, ${ }^{1}$ Ryan B. Cohen, BS, ${ }^{2}$ Jason Cohen, BS, ${ }^{3}$ Babak Kahndehroo, MD, ${ }^{1}$ Sheila Kahwaty, PA-C, ${ }^{1}$ Eli Baron, MD ${ }^{1}$

${ }^{1}$ Cedars Sinai Medical Center, Los Angeles, CA, ${ }^{2}$ Boston University School of Medicine, Boston, MA, ${ }^{3}$ Albert Einstein College of Medicine, New York, NY

\section{Abstract}

\section{Background}

CMIS techniques are heavily dependent on placement of lateral interbody cages. Cages with an increased lordotic angle are being advocated to improve segmental lordosis and SVA. We assessed the segmental lordosis achieved with the individual cages. We further studied three variables and the effect each had on segmental lordosis: the lordosis angle of the cage, the position of the cage in the intervertebral space, and the level that it has been placed.

\section{Methods}

This is a retrospective study of 66 consecutive patients who underwent lateral interbody fusion using lordotic cages as part of CMIS correction of scoliosis from June 2012 to January 2016. Standing radiographs at pre op and 6-week follow-up were reviewed to identify the position of the cage in the intervertebral space and the amount of segmental lordosis achieved.

\section{Results}

A total of 224 cages were placed. The $6^{\circ}, 10^{\circ}, 12^{\circ}$, and $20^{\circ}$ cages achieved a mean segmental lordosis of $9.00^{\circ}$, $13.09^{\circ}, 13.23^{\circ}$, and $18.32^{\circ}$, respectively $(\mathrm{P}<.05)$. Additionally, cages placed in the anterior, middle, and posterior 3 rd of the disk space produced $13.02^{\circ}, 11.47^{\circ}$, and $8.23^{\circ}$ of lordosis, respectively $(\mathrm{P}<.05)$. Stratifying by level, cages placed at T12-L1, L1-2, L2-3, L3-4, and L4-5 translated to mean segmental lordotic values of $8.43^{\circ}, 10.02^{\circ}$, $11.38^{\circ}, 12.91^{\circ}$, and $14.58^{\circ}$, respectively $(\mathrm{P}<.05)$.

\section{Conclusions}

The angle of the cage had an impact on segmental lordosis. Achieved segmental lordosis was notably more when the cage was placed in lower lumbar levels. Additionally, cages placed in the posterior 3rd of the intervertebral space had significantly worse segmental lordosis compared to those placed in the anterior or middle 3rd. Our study shows that an average delta change of $8.03^{\circ}$ can be achieved with $12^{\circ}$ cages and this when done at each subsequent level results in a progressive harmonious creation of lordosis.

IRB approval was obtained for this study.

MINIMALLY INVASIVE SURGERY

KEYWORDS: CMIS, MINIMALLY INVASIVE, CAGES, LORDOTIC, SEGMENTAL LORDOSIS, INTERBODY FUSION, HYPERLORDOTIC, ADULT SPINAL DEFORMITY VOLUME 11 ISSUE 3 DOI: $10.14444 / 4023$ PAGES $183-192$

\section{Introduction}

Circumferential Minimally Invasive Spinal (CMIS) correction of adult spinal deformity (ASD) has emerged as a novel, less-invasive alternative to traditional open surgery. There are many advantages to a minimally invasive surgical (MIS) approach including less blood loss, lower complication rates, and improved cosmesis..$^{1-10}$ Nonetheless, widespread adoption of CMIS correction has been limited by a steep learning curve $\mathrm{e}^{11,12}$ and the relative inability to achieve a robust sagittal alignment. ${ }^{13-17}$

The standard open approach for correction of ASD relies on posterior osteotomies to accomplish adequate lordosis. ${ }^{18-23}$ This relatively invasive solution requires broad exposure of the posterior anatomy and widespread tissue destruction. ${ }^{24-27}$ Despite its invasiveness, open correction can achieve superior sagittal balance as compared to early reports of CMIS. ${ }^{13-17}$ 
As a result, there has been a bias amongst surgeons to reserve CMIS correction for cases with minimal sagittal deformity. ${ }^{16,28}$ Considering the importance of sagittal balance on functional outcome, CMIS correction needs ways to attain greater correction in the sagittal plane. ${ }^{29-33}$

Novel innovations have been introduced to tackle the problem of sagittal alignment. These include anterior column realignment (ACR), ${ }^{34-41}$ rod contouring, ${ }^{42,43}$ and the utilization of hyperlordotic cages. ${ }^{34,38}$ These are designed to maximize the sagittal correction achievable with CMIS techniques while maintaining the many benefits that MIS operations offer. Although they show promise, the efficacy of these new approaches has not been well studied.

Our analysis focused specifically on the use of hyperlordotic cages. It is known that angled cages improve lordosis and subsequent spino-pelvic harmony. However, the influence of specific cage factors has not been well studied. We focused on 3 parameters of these cages: (1) angle of the cage, (2) relative position in the disc space, and (3) the spinal level of cage placement. We quantified the gains in sagittal alignment using hyperlordotic cages and looked at the influence of these three parameters.

\section{Materials and methods}

This is a single center study from a prospective database of patients who underwent CMIS correction for ASD (Cobb angle $>20$ degrees or SVA $>50 \mathrm{~mm}$ or PI/LL mismatch $>10$ ) by the senior author from June 2012 to January 2016. Internal Review Board approval was obtained.

Only patients with 2 or more levels fused were included. Indications for surgery included symptomatic back and/or leg pain attributed to ASD that was unresponsive to conservative measures. All patients were treated with MIS strategies using MIS Lateral Lumbar Interbody Fusion (LLIF) with percutaneous pedicle screw and rod instrumentation. Details of our techniques have been extensively published before. ${ }^{2,5,6,44-52}$ Patients were instrumented at each level with either a $6^{\circ}, 10^{\circ}, 12^{\circ}$, or $20^{\circ}$ hyperlordotic cages. At L4-5 and L3-4, all patients had a $12^{\circ}$ cage placed. At L2-3, patients had either a $6^{\circ}, 10^{\circ}$ or $12^{\circ}$ degree cage based on the amount of sagittal correction needed. At L1-2 and T12-L1, usually a $6^{\circ}$ or $10^{\circ}$ cage was used. A few patients had ALL release and a $20^{\circ}$ cage was used. At L5-S1 an ALIF was done. Patients who underwent posterior osteotomies were excluded from the study. 66 patients were identified who met the inclusion criteria.

Radiographic measures were assessed using fulllength 36-inch radiographs at the time of enrollment and 6-week follow-up. Few patients had inadequate or unavailable 6-week follow-up, so earliest follow-up imaging was used. Segmental lordosis at each level was defined as the angle created by the upper end plate of the lower vertebrae and the lower end plate of the upper vertebrae. Regional lumbar lordosis was measured as the Cobb angle between the upper end plate of $\mathrm{L} 1$ and the upper end plate of S1.

The position of the implant was decided by dividing the inferior vertebral body into three parts and the position was determined as to what third of the body the prosthesis predominantly occupied.

\section{Statistical Methods}

Lumbar lordosis and segmental lordosis at pre op and post op for the entire patient pool was compared using T-testing. In 3 separate analyses, the data was stratified based on (1) lordotic angle of the cage, (2) relative position in the disc space, and (3) the spinal level of cage placement. For each of these parameters, mean pre op, post op, and delta segmental lordosis was calculated. Pre op values were compared to post op values using T-testing. Mean post op segmental lordosis was compared between groups in each parameter using ANOVA analysis. Statistical analyses were 2 -sided and $\mathrm{p}<0.05$ was considered statistically significant. All statistical analysis was conducted using SPSS (Version 22).

\section{Results}

Table 1 shows demographic information. For the 66 patients who met inclusion criteria, the mean age was 66.08 (SD 8.22, Range 48-84). The mean number of levels fused with LLIF was 3.39 (SD 0.99, Range 2-5). A total of 224 cages were placed. Table 2 
stratifies the total number of cages based on lordotic angle, relative position in the disc space, and spinal level of placement.

For the total patient pool, mean lumbar lordosis at pre op and at immediate post op was $39.43^{\circ}$ and $49.32^{\circ}$, respectively. Table 3 shows mean segmental lordosis and lumbar lordosis figures for all cages placed in the study.

Placement of $6^{\circ}, 10^{\circ}, 12^{\circ}$, and $20^{\circ}$ cages yielded post op segmental lordotic angles of $9.00^{\circ}, 13.09^{\circ}, 13.23^{\circ}$, and $18.32^{\circ}$, respectively. Anteriorly, middle, and posteriorly placed cages produced $13.02^{\circ}, 11.47^{\circ}$, and $8.23^{\circ}$ of post op lordosis, respectively. Instrumentation at T12-L1, L1-L2, L2-L3, L3-L4, and L4-L5 translated to mean post op segmental lordotic values of $8.43^{\circ}, 10.02^{\circ}, 11.38^{\circ}, 12.91^{\circ}$, and $14.58^{\circ}$, respectively. The mean post op values were statistically significant between all groups using ANOVA analysis. Moreover, all mean post op values were statistically significant compared to pre op figures. Tables 4-6 stratify pre op and post op segmental lordosis based

Table 1. Demographic information.

\begin{tabular}{|l|r|}
\hline Number of Patients & 66 \\
\hline Mean Age & $66.08(48-84)$ \\
\hline Total LLIF Levels & 224 \\
\hline Mean Levels & 3.39 \\
\hline
\end{tabular}

Table 2. Total number of cages stratified by lordosis, position, and spinal level.

\begin{tabular}{|l|r|r|r|r|r|}
\hline Lordosis & Cages & Position & Cages & Spinal Level & Cages \\
\hline $6^{\circ}$ & 58 & Anterior & 111 & T12-L1 & 14 \\
\hline $10^{\circ}$ & 31 & Middle & 110 & L1-2 & 36 \\
\hline $12^{\circ}$ & 130 & Posterior & 3 & L2-3 & 56 \\
\hline $20^{\circ}$ & 5 & & & L3-4 & 64 \\
\hline & & & & L4-5 & 54 \\
\hline Total & 224 & & 224 & & 224 \\
\hline
\end{tabular}

Table 3. Mean Segmental Lordosis and Global Lumbar Lordosis for Entire Cohort.

\begin{tabular}{|l|r|r|r|r|}
\hline & Preoperative & Postoperative & Delta & P value \\
\hline Mean Segmental Lordosis & 4.23 & 12.17 & 7.95 & $.000^{*}$ \\
\hline Mean Lumbar Lordosis & 39.43 & 49.32 & 10.05 & $.000^{*}$ \\
\hline
\end{tabular}

on lordotic angle (Table 4), relative position in the disc space (Table 5), and spinal level of placement (Table 6). Figures reflect preoperative (Figure 1), intraoperative (Figure 2), and postoperative (Figure 3) radiographs of a patient who underwent CMIS correction with 2-level cage placement.

\section{Discussion}

Achieving adequate correction in the sagittal plane has often been quoted as the most significant shortcoming of the CMIS philosophy; all the more important considering sagittal imbalance is the primary driver of clinical outcome in ASD patients..$^{29-33}$ Mechanistically, excessive stress secondary to imbalance in the sagittal plane exhausts the posterior spinal muscles, translating to lower back pain..$^{34,53,54}$ We propose 3 augmenting strategies for CMIS correction of sagittal balance using hyperlordotic cages: (1) utilizing appropriately angled cages, (2) anterior positioning of the implant in the disc space, and (3) concentrating

\begin{tabular}{|c|c|c|c|c|}
\hline \multirow[b]{2}{*}{ Lordosis } & \multicolumn{2}{|c|}{ Mean Segmental Lordosis } & \multirow[b]{2}{*}{ Delta } & \multirow[b]{2}{*}{$P$ value } \\
\hline & Preoperative & Postoperative & & \\
\hline $6^{\circ}$ & 1.74 & $\begin{array}{l}9.00(4.09-20.26, \mathrm{SD} \\
3.64)\end{array}$ & 7.26 & $.000^{*}$ \\
\hline $10^{\circ}$ & 5.00 & $\begin{array}{l}13.09(6.07-20.57, \text { SD } \\
3.12)\end{array}$ & 8.08 & $.000^{*}$ \\
\hline $12^{\circ}$ & 5.18 & $\begin{array}{l}13.23(4.79-25.38, \mathrm{SD} \\
3.38)\end{array}$ & 8.03 & $.000^{*}$ \\
\hline $20^{\circ}$ & 4.10 & $\begin{array}{l}18.23(16.77-19.75, \mathrm{SD} \\
1.28)\end{array}$ & 14.22 & $.000^{*}$ \\
\hline \multicolumn{2}{|c|}{$\begin{array}{l}\text { ANOVA Postoperative between } \\
\text { groups: }\end{array}$} & $.000^{*}$ & & \\
\hline
\end{tabular}

Table 5. Mean segmental lordosis grouped by relative position of cage in disc space.

\begin{tabular}{|l|l|l|l|l|}
\hline \multicolumn{4}{|l|}{ Mean Segmental Lordosis } & \multicolumn{2}{l|}{} \\
\hline Position & Preoperative & Postoperative & Delta & P value \\
\hline Anterior & 4.65 & $\begin{array}{l}13.02(4.79-25.38, \mathrm{SD} \\
3.58)\end{array}$ & 8.36 & $.000^{*}$ \\
\hline Middle & 3.89 & $\begin{array}{l}11.47(4.09-19.75, \mathrm{SD} \\
4.12)\end{array}$ & 7.58 & $.000^{*}$ \\
\hline \begin{tabular}{l} 
Posterior \\
\hline
\end{tabular} & 1.52 & $\begin{array}{l}8.23(5.96-11.43, \mathrm{SD} \\
2.85)\end{array}$ & 6.71 & $.036^{*}$ \\
\hline $\begin{array}{l}\text { ANOVA Postoperative between } \\
\text { groups: }\end{array}$ & & $.000^{*}$ & & \\
\hline
\end{tabular}


on lower level lumbar cage placement.

Standard open procedures rely on posterior osteotomies to achieve alignment in the sagittal plane. In order of increasing invasiveness, these include Smith-Peterson Osteotomy (SPO), Pedicle Subtraction Osteotomy (PSO), and Vertebral Column Resection (VCR). SPO is a relatively safe and technically easy procedure that provides about $10^{\circ}$ of lordosis per level. ${ }^{55}$ Nonetheless, complications including rupture of the great vessels have been reported. PSO and VCR are more difficult techniques, though tried and effective means of achieving sagittal balance. They can achieve $25^{\circ}-40^{\circ 19,20,56}$ and upwards of $45^{\circ 57}$ of lordosis per level, respectively. However they are associated with significant morbidity and high-risk complications. ${ }^{58-63}$

In an early study, Deukmedjian et al. reported on the feasibility of a minimally invasive lateral retroperitoneal transpsoas approach to anterior longitudinal ligament (ALL) release as an alternative to posterior osteotomies. Seven patients undergoing ALL release resulted in a mean increase in segmental lordosis and global lumbar lordosis of $10.2^{\circ}$ and $25^{\circ}$, respectively. ${ }^{40}$

In a retrospective case series of 17 patients who underwent anterior column realignment (ACR) by Akbarnia et al., the mean motion segment angle improved $35^{\circ}$ from pre op to post op. Of note, 15 of the

Table 6. Mean segmental lordosis grouped by spinal level of cage placement.

\begin{tabular}{|c|c|c|c|c|}
\hline \\
\hline \multirow[b]{2}{*}{ Level } & \multicolumn{2}{|c|}{ Mean Segmental Lordosis } & \multirow[b]{2}{*}{ Delta } & \multirow[b]{2}{*}{$\mathrm{P}$ valu } \\
\hline & Preoperative & Postoperative & & \\
\hline T12-L1 & .98 & $\begin{array}{l}8.43(4.09-15.93, \mathrm{SD} \\
2.92)\end{array}$ & 7.44 & $.000^{*}$ \\
\hline L1-2 & 1.91 & $\begin{array}{l}10.02(4.42-20.26, \mathrm{SD} \\
3.99)\end{array}$ & 8.12 & $.000^{*}$ \\
\hline $\mathrm{L} 2-3$ & 3.67 & $\begin{array}{l}11.38(4.79-18.87, \mathrm{SD} \\
3.74)\end{array}$ & 7.71 & $.000^{*}$ \\
\hline L3-4 & 4.82 & $\begin{array}{l}12.91(5.96-25.38, \mathrm{SD} \\
3.60)\end{array}$ & 8.08 & $.000 *$ \\
\hline L4-5 & 6.53 & $\begin{array}{l}14.58(6.92-20.79, \text { SD } \\
2.98)\end{array}$ & 8.05 & $.000^{*}$ \\
\hline \multicolumn{2}{|c|}{$\begin{array}{l}\text { ANOVA Postoperative between } \\
\text { groups: }\end{array}$} & $.000^{*}$ & & \\
\hline
\end{tabular}

patients had an SPO at the ACR level. Compared to posterior-based approaches, the study showed similar correction capacity including segmental mea-

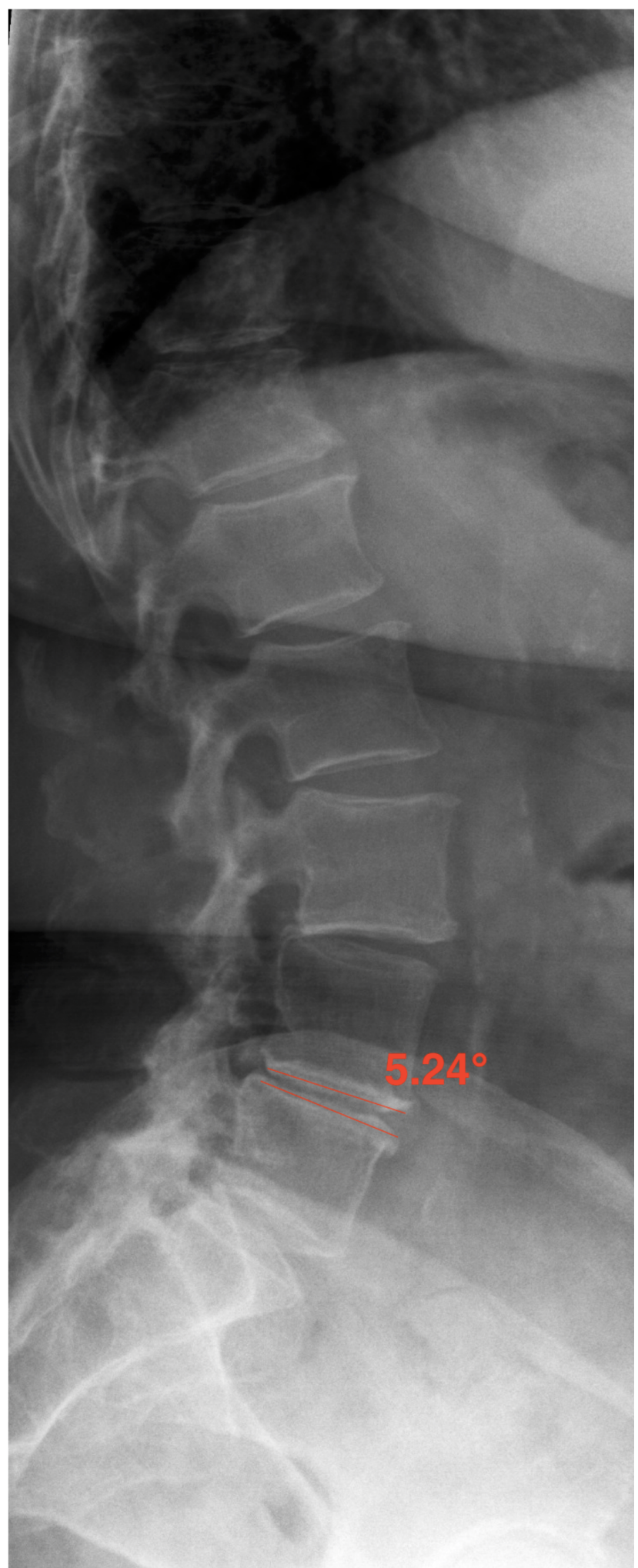

Fig. 1. Preoperative sagittal image of lumbar spine before CMIS correction with hyperlordotic cages. 
sures, lumbar lordosis, and sagittal balance. ${ }^{37}$

A cadaveric study by Uribe et al. looked at varying degrees of lordotic implants on segmental lordosis using the minimally invasive lateral retroperitoneal trans-psoas approach (XLIF). After ALL release, without posterior osteotomies, post-implantation increases in segmental lordosis using $10^{\circ}, 20^{\circ}$, and $30^{\circ}$ cages were $4.1^{\circ}, 9.5^{\circ}$, and $11.6^{\circ}$, respectively. Mean lumbar lordosis was $33.7^{\circ}, 43.8^{\circ}$, and $50.3^{\circ}$, respectively. ${ }^{38}$

In a review of 40 patients, Sembrano et al compared $10^{\circ}$ lordotic cages to non-lordotic cages. The group found a significant increase in segmental lordosis at the operative level using $10^{\circ}$ cages. However, overall lumbar lordosis remained unchanged.

Anand et al. ${ }^{17}$ quantified the ceiling effects of CMIS correction in a prior study that included $0^{\circ}$ and $6^{\circ}$ cages done prior to 2011. In a retrospective study of 90 patients who underwent CMIS correction without osteotomies or ALL release, the study showed an SVA correction ceiling effect of $89 \mathrm{~mm}$. Osteotomies were considered only when pre op SVA was greater than $100 \mathrm{~mm}$ and substantial lumbar lordosis was needed.

In this study, using $6^{\circ}, 10^{\circ}, 12^{\circ}$, and $20^{\circ}$ cages yielded

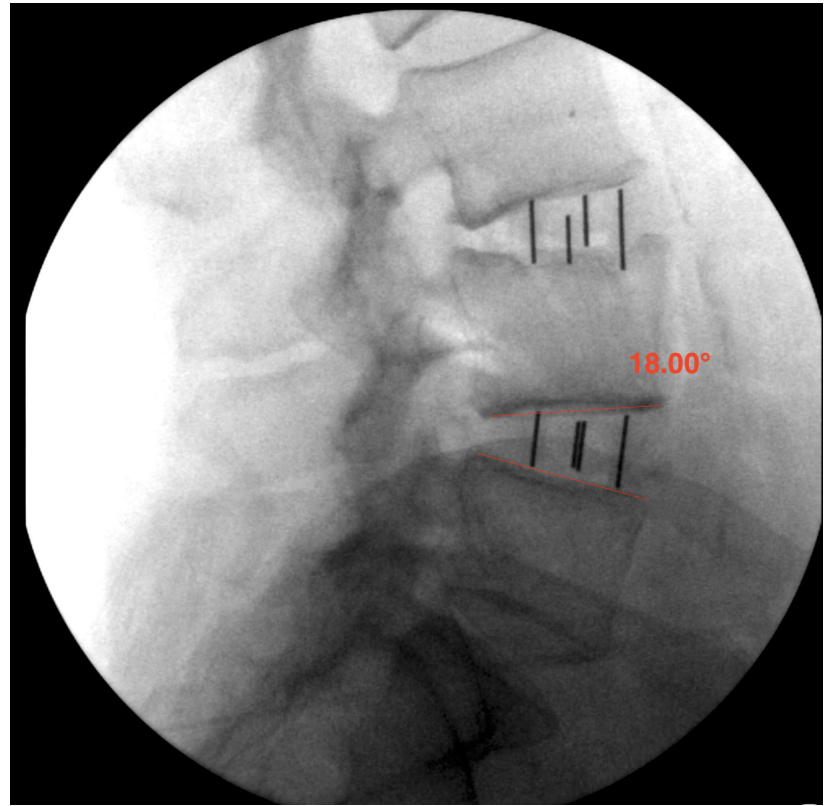

Fig. 2. Intraoperative fluoroscopy after placement of $12^{\circ}$ cages at L3-4 and L4-5. post op segmental lordotic angles of $9.00^{\circ}, 13.09^{\circ}$, $13.23^{\circ}$, and $18.32^{\circ}$, respectively. The data demonstrates a positive trend between instrumented cage

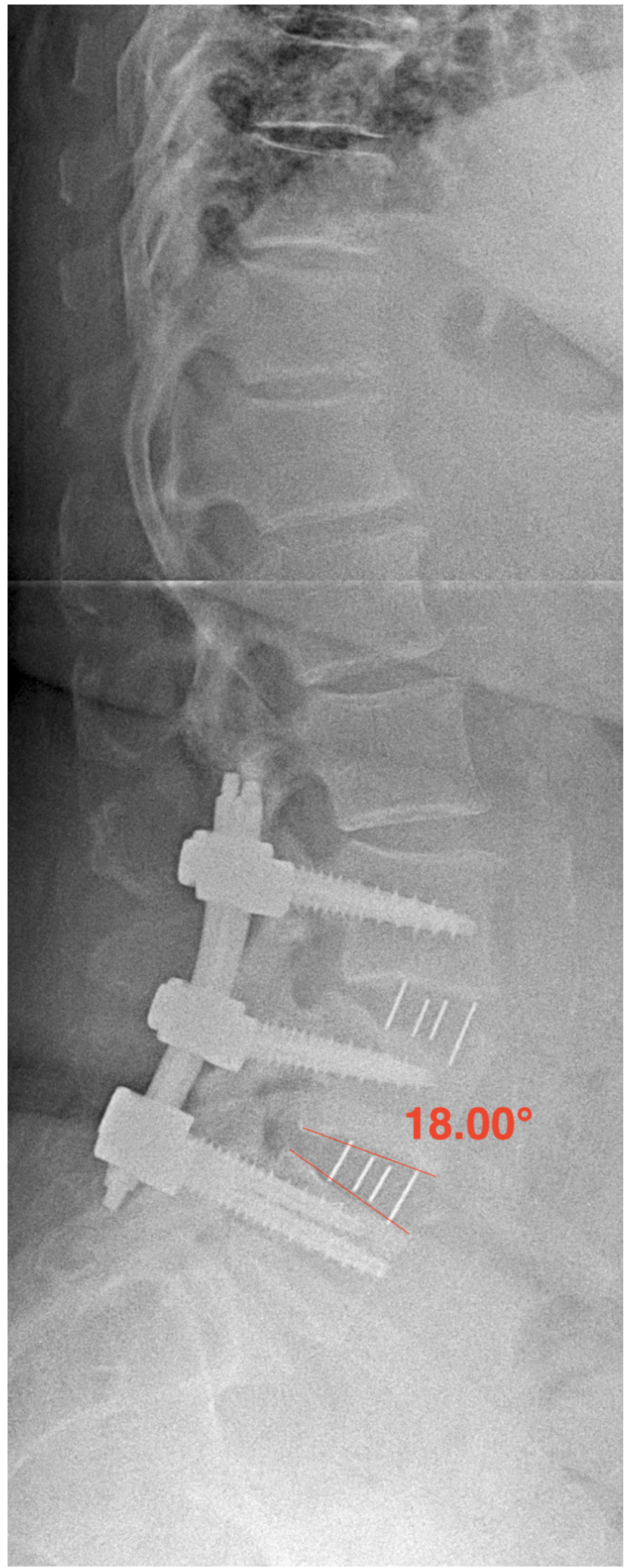

Fig. 3. Postoperative sagittal image of lumbar spine after 2-level cage placement. Segmental lordosis of $18^{\circ}$ was achieved at L4-5. 
angles and post op lordotic gains. Compared to each other, the post op lordotic angles are statistically significant $(\mathrm{p}<.05)$. Considering the findings, surgeons may elect to use increasingly lordotic cages when robust sagittal alignment is required. Nonetheless, there are important limitations in cage angle to consider. Extreme angled lordotic cages, including $20^{\circ}$ and $30^{\circ}$ cages, introduce certain mechanistic challenges by interrupting the natural curvature of the spine, point loading the endplate, and compromising contact between the cage-bone interphase. ${ }^{34}$ Moreover, gains in segmental lordosis reach a threshold as higher-level implants are eventually limited by the posterior elements of the vertebrae. Mirroring this point, the $20^{\circ}$ cage in our study produced only $18.32^{\circ}$ of lordosis post op. This is the only cage in our analysis that yielded a post op segmental measure shy of its known lordotic angle.

Our study shows that a delta change on an average of $8.03^{\circ}$ (Table 4 ) can be achieved with the $12^{\circ}$ cages and this when done at each subsequent level results in a progressive harmonious creation of lordosis. We propose the $12^{\circ}$ cage as the optimal compromise between lordotic gain and mechanistic challenge. When possible, placing the $12^{\circ}$ cage anteriorly achieves significant lordosis that can be augmented beyond its known angle especially at L4-5 and L3-4. More importantly, it avoids the drawbacks of higher level $20^{\circ}$ and $30^{\circ}$ instrumentation such as anterior point loading. When considering multi-level fusions that require extreme correction in the sagittal plane we avoid fusion with exceedingly lordotic implants but rather perform multi-level instrumentation with the use of $12^{\circ}$ cages to help achieve a harmonious correction that follows the natural curvature of the spine. Figures show a Circumferential MIS correction at preoperative (Figure 4) and postoperative (Figure 5) using $12^{\circ}$ cages at each level.

Between posterior, middle, and anterior placed cages there was a positive trend between post op segmental lordosis of $8.23^{\circ}, 11.47^{\circ}$, and $13.02^{\circ}$ with anterior placement. When compared to each other these figures were statistically significant on ANOVA $(\mathrm{P}<$ $.05)$. Cages placed anteriorly demonstrated the highest mean delta at $8.36^{\circ}$ (Table 5). Considering the phenomenon mechanistically, anteriorly placing the cage shifts the fulcrum of curvature along the disc space anteriorly and produces a cantilever effect. In our experience, this strategy provides a relatively easy and intuitive method of incrementally increasing sagittal gains.

The level of cage placement also demonstrated significant trends with respect to segmental lordosis. Moving caudally, T12-L1, L1-L2, L2-L3, L3-L4, L4-L5 produced increasing post op lordotic angles of $8.43^{\circ}, 10.02^{\circ}, 11.38^{\circ}, 12.91^{\circ}$, and $14.58^{\circ}$. These post op figures were statistically significant between groups on ANOVA. $(\mathrm{P}<.05)$ Considering such impressive gains, the L3-L4 and L4-L5 disc spaces are especially attractive targets for hyperlordotic cage instrumentation. Lower level instrumentation must be capitalized on to achieve harmonious instrumentation with as much correction as possible.

Our data is limited in the number of posteriorly placed and higher $20^{\circ}$ and $30^{\circ}$ constructs. Further studies are needed to directly compare sagittal gains using lower level $6^{\circ}, 10^{\circ}$, and $12^{\circ}$ cages with these higher level angled implants. Also, whether the use of these augmenting strategies improves disability

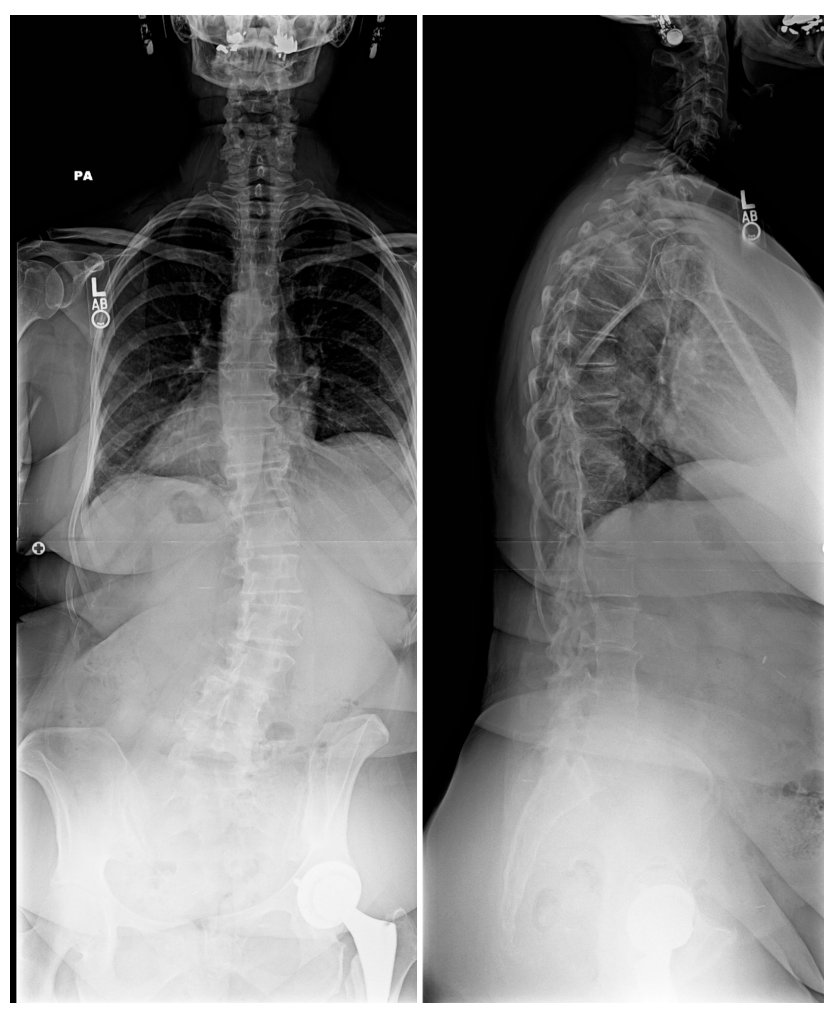

Fig. 4. Preoperative XR imaging before placement of $12^{\circ}$ cages for multilevel CMIS correction. 
and overall clinical outcomes remains unknown.

Our analysis was based on a 6-week radiographic follow-up window. Our results do not reflect the influence of future subsidence on the loss of segmental lordosis past this follow-up endpoint. Future studies with longer follow-up are required to quantify the effect of graft subsidence on overall correction.

In our experience, current applications of interbody cages in CMIS correction underestimate the potential for sagittal correction. Specific augmenting strategies, including anterior placement of the cage in the disc space and lower level instrumentation can maximize segmental gains. We prefer $12^{\circ}$ cages as an appropriate balance between lordotic gain and mechanistic limitation. Our overall strategy relies on multilevel instrumentation with anterior positioned $12^{\circ}$ lordotic cages, providing a harmonious correction that follows the natural curvature of the spine. Along with rod contouring, these strategies can further eliminate the invasiveness of osteotomies, paving the way for truly minimally invasive methods of achiev-

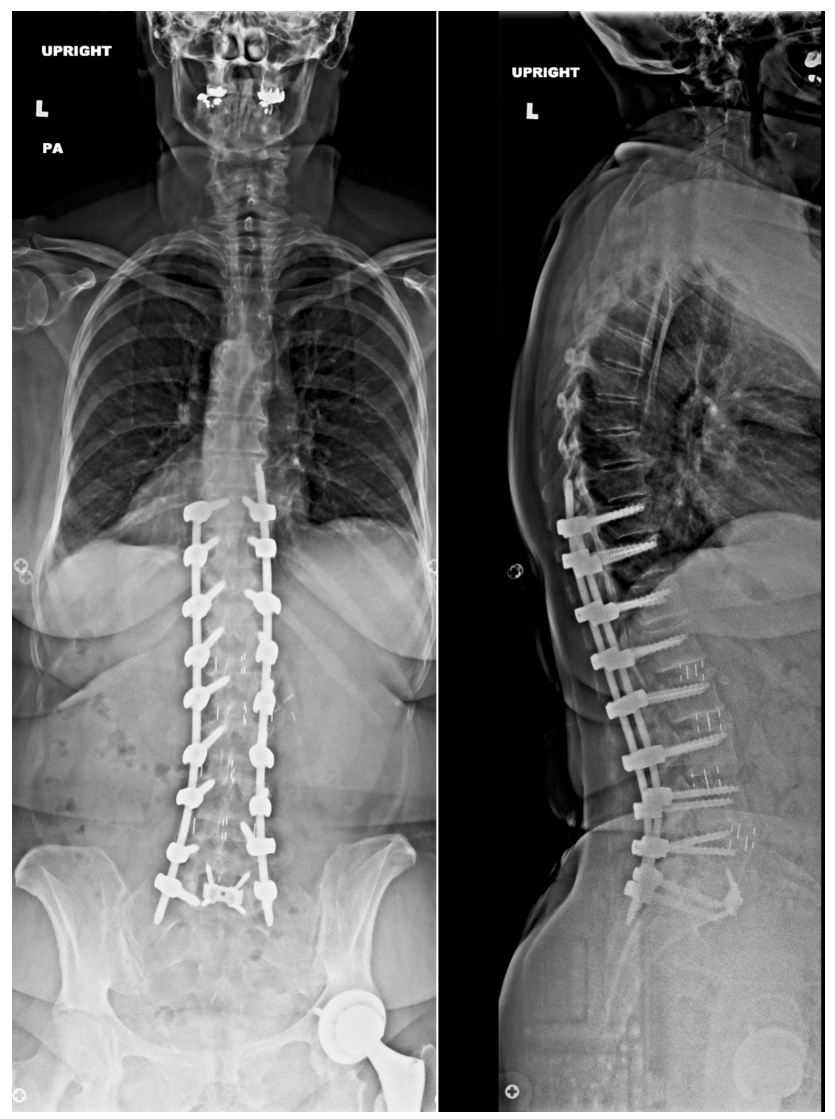

Fig. 5. Postoperative XR imaging after placement of $12^{\circ}$ cages for multilevel CMIS correction. ing sagittal correction.

\section{References}

1. Anand N, Baron EM, Khandehroo B. Is circumferential minimally invasive surgery effective in the treatment of moderate adult idiopathic scoliosis? Clinical Orthopaedics and Related Research ${ }^{\circledR}$. 2014;472(6):1762-1768.

2. Anand N, Baron EM, Khandehroo B, Kahwaty S. Long-term 2- to 5-year clinical and functional outcomes of minimally invasive surgery for adult scoliosis. Spine. 2013;38(18):1566-1575.

3. Wang MY, Mummaneni PV. Minimally invasive surgery for thoracolumbar spinal deformity: initial clinical experience with clinical and radiographic outcomes. Neurosurgical focus. 2010;28(3):E9.

4. Isaacs RE, Hyde J, Goodrich JA, Rodgers WB, Phillips FM. A prospective, nonrandomized, multicenter evaluation of extreme lateral interbody fusion for the treatment of adult degenerative scoliosis: perioperative outcomes and complications. Spine. 2010;35(26 Suppl):S322-330.

5. Anand N, Rosemann R, Khalsa B, Baron EM. Mid-term to long-term clinical and functional outcomes of minimally invasive correction and fusion for adults with scoliosis. Neurosurgical focus. 2010;28(3):E6.

6. Anand N, Baron EM, Thaiyananthan G, Khalsa $\mathrm{K}$, Goldstein TB. Minimally invasive multilevel percutaneous correction and fusion for adult lumbar degenerative scoliosis: a technique and feasibility study. Journal of spinal disorders \& techniques. 2008;21(7):459-467.

7. Park Y, Ha JW. Comparison of one-level posterior lumbar interbody fusion performed with a minimally invasive approach or a traditional open approach. Spine. 2007;32(5):537-543.

8. Foley KT, Holly LT, Schwender JD. Minimally invasive lumbar fusion. Spine. 2003;28(15 Suppl):S26-35.

9. Khoo LT, Palmer S, Laich DT, Fessler RG. Minimally invasive percutaneous posterior lumbar interbody fusion. Neurosurgery. 2002;51(5 Suppl):S166-181.

10. Regan JJ, Yuan H, McAfee PC. Laparoscopic fusion of the lumbar spine: minimally invasive spine 
surgery. A prospective multicenter study evaluating open and laparoscopic lumbar fusion. Spine. 1999;24(4):402-411.

11. Sclafani JA, Kim CW. Complications associated with the initial learning curve of minimally invasive spine surgery: a systematic review. Clinical orthopaedics and related research. 2014;472(6):1711-1717. 12. Wang $\mathrm{H}$, Huang B, Li C, et al. Learning curve for percutaneous endoscopic lumbar discectomy depending on the surgeon's training level of minimally invasive spine surgery. Clinical neurology and neurosurgery. 2013;115(10):1987-1991.

13. Park P, Wang MY, Lafage V, et al. Comparison of two minimally invasive surgery strategies to treat adult spinal deformity. Journal of neurosurgery Spine. 2015;22(4):374-380.

14. Wang MY, Mummaneni PV, Fu KM, et al. Less invasive surgery for treating adult spinal deformities: ceiling effects for deformity correction with 3 different techniques. Neurosurgical focus. 2014;36(5):E12. 15. Haque RM, Mundis GM, Jr., Ahmed Y, et al. Comparison of radiographic results after minimally invasive, hybrid, and open surgery for adult spinal deformity: a multicenter study of 184 patients. $\mathrm{Neu}$ rosurgical focus. 2014;36(5):E13.

16. Deukmedjian AR, Ahmadian A, Bach K, Zouzias A, Uribe JS. Minimally invasive lateral approach for adult degenerative scoliosis: lessons learned. Neurosurgical focus. 2013;35(2):E4. 17. Anand N, Baron EM, Khandehroo B. Limitations and ceiling effects with circumferential minimally invasive correction techniques for adult scoliosis: analysis of radiological outcomes over a 7-year experience. Neurosurgical focus. 2014;36(5):E14. 18. Berjano P, Aebi M. Pedicle subtraction osteotomies (PSO) in the lumbar spine for sagittal deformities. European spine journal : official publication of the European Spine Society, the European Spinal Deformity Society, and the European Section of the Cervical Spine Research Society. 2015;24 Suppl 1:S49-57. 19. Bridwell KH. Decision making regarding SmithPetersen vs. pedicle subtraction osteotomy vs. vertebral column resection for spinal deformity. Spine. 2006;31(19 Suppl):S171-178.

20. Bridwell KH, Lewis SJ, Rinella A, Lenke LG, Baldus C, Blanke K. Pedicle subtraction osteotomy for the treatment of fixed sagittal imbalance. Surgical technique. The Journal of bone and joint surgery American volume. 2004;86-A Suppl 1:44-50.

21. Cho KJ, Bridwell KH, Lenke LG, Berra A, Baldus C. Comparison of Smith-Petersen versus pedicle subtraction osteotomy for the correction of fixed sagittal imbalance. Spine. 2005;30(18):2030-2037; discussion 2038.

22. Gill JB, Levin A, Burd T, Longley M. Corrective osteotomies in spine surgery. The Journal of bone and joint surgery American volume.

2008;90(11):2509-2520.

23. Schwab FJ, Patel A, Shaffrey CI, et al. Sagittal realignment failures following pedicle subtraction osteotomy surgery: are we doing enough?: Clinical article. Journal of neurosurgery Spine.

2012;16(6):539-546.

24. Gejo R, Matsui H, Kawaguchi $Y$, Ishihara H, Tsuji H. Serial changes in trunk muscle performance after posterior lumbar surgery. Spine.

1999;24(10):1023-1028.

25. Kawaguchi Y, Matsui H, Tsuji H. Back muscle injury after posterior lumbar spine surgery. A histologic and enzymatic analysis. Spine.

1996;21(8):941-944.

26. Kawaguchi Y, Yabuki S, Styf J, et al. Back muscle injury after posterior lumbar spine surgery. Topographic evaluation of intramuscular pressure and blood flow in the porcine back muscle during surgery. Spine. 1996;21(22):2683-2688.

27. Styf JR, Willen J. The effects of external compression by three different retractors on pressure in the erector spine muscles during and after posterior lumbar spine surgery in humans. Spine. 1998;23(3):354-358.

28. Mummaneni PV, Shaffrey CI, Lenke LG, et al. The minimally invasive spinal deformity surgery algorithm: a reproducible rational framework for decision making in minimally invasive spinal deformity surgery. Neurosurgical focus. 2014;36(5):E6.

29. Lu Y, Falcone MM, Wang MY, Wu S. Multilevel TLIF for Spinal Deformity. Minimally Invasive Spinal Deformity Surgery: Springer; 2014:173-183.

30. Knox JB, Lonner BS. Sagittal Balance. Minimally Invasive Spinal Deformity Surgery: Springer; 2014:33-37.

31. Lee JS, Lee HS, Shin JK, Goh TS, Son SM. Prediction of sagittal balance in patients with osteoporo- 
sis using spinopelvic parameters. European spine journal : official publication of the European Spine Society, the European Spinal Deformity Society, and the European Section of the Cervical Spine Research Society. 2013;22(5):1053-1058.

32. Glassman SD, Bridwell K, Dimar JR, Horton W, Berven S, Schwab F. The impact of positive sagittal balance in adult spinal deformity. Spine.

2005;30(18):2024-2029.

33. Glassman SD, Berven S, Bridwell K, Horton W, Dimar JR. Correlation of radiographic parameters and clinical symptoms in adult scoliosis. Spine. 2005;30(6):682-688.

34. Uribe JS, Harris JE, Beckman JM, Turner AW, Mundis GM, Akbarnia BA. Finite element analysis of lordosis restoration with anterior longitudinal ligament release and lateral hyperlordotic cage placement. European spine journal: official publication of the European Spine Society, the European Spinal Deformity Society, and the European Section of the Cervical Spine Research Society. 2015;24 Suppl 3:420-426.

35. Wang MY. The Importance of the Fractional Curve. Minimally Invasive Spinal Deformity Surgery: Springer; 2014:47-52.

36. Manwaring JC, Bach K, Ahmadian AA, Deukmedjian AR, Smith DA, Uribe JS. Management of sagittal balance in adult spinal deformity with minimally invasive anterolateral lumbar interbody fusion: a preliminary radiographic study. Journal of neurosurgery Spine. 2014;20(5):515-522.

37. Akbarnia BA, Mundis GM, Jr., Moazzaz P, et al. Anterior column realignment (ACR) for focal kyphotic spinal deformity using a lateral transpsoas approach and ALL release. Journal of spinal disorders \& techniques. 2014;27(1):29-39.

38. Uribe JS, Smith DA, Dakwar E, et al. Lordosis restoration after anterior longitudinal ligament release and placement of lateral hyperlordotic interbody cages during the minimally invasive lateral transpsoas approach: a radiographic study in cadavers. Journal of neurosurgery Spine.

2012;17(5):476-485.

39. Deukmedjian AR, Le TV, Baaj AA, Dakwar E, Smith DA, Uribe JS. Anterior longitudinal ligament release using the minimally invasive lateral retroperitoneal transpsoas approach: a cadaveric feasibility study and report of 4 clinical cases. Journal of neuro- surgery Spine. 2012;17(6):530-539.

40. Deukmedjian AR, Dakwar E, Ahmadian A, Smith DA, Uribe JS. Early outcomes of minimally invasive anterior longitudinal ligament release for correction of sagittal imbalance in patients with adult spinal deformity. TheScientificWorldJournal. 2012;2012:789698.

41. Berjano P, Damilano M, Lamartina C. Sagittal alignment correction and reconstruction of lumbar post-traumatic kyphosis via MIS lateral approach. European spine journal : official publication of the European Spine Society, the European Spinal Deformity Society, and the European Section of the Cervical Spine Research Society. 2012;21(12):2718-2720.

42. Shen F, Zhou B, Li Q, et al. Posterior-only spinal release combined with derotation, translation, segmental correction, and an in situ rod-contouring technique for treatment of severe and rigid scoliosis. Journal of neurosurgery Spine. 2015;22(2):194-198. 43. Demura S, Murakami H, Hayashi H, et al. Influence of Rod Contouring on Rod Strength and Stiffness in Spine Surgery. Orthopedics.

2015;38(6):e520-523.

44. Anand N, Baron EM. Role of dynesys as pedicle-based nonfusion stabilization for degenerative disc disorders. Advances in orthopedics.

2012;2012:218385.

45. Anand N, Baron EM. Urological injury as a complication of the transpsoas approach for discectomy and interbody fusion. Journal of neurosurgery Spine. 2013;18(1):18-23.

46. Anand N, Baron EM. Minimally invasive approaches for the correction of adult spinal deformity. European spine journal : official publication of the European Spine Society, the European Spinal Deformity Society, and the European Section of the Cervical Spine Research Society. 2013;22 Suppl 2:S232-241.

47. Anand N, Baron EM, Bray RS, Jr. Benefits of the paraspinal muscle-sparing approach versus the conventional midline approach for posterior nonfusion stabilization: comparative analysis of clinical and functional outcomes. SAS journal. 2007;1(3):93-99. 48. Anand N, Baron EM, Bray RS, Jr. Modified muscle-sparing paraspinal approach for stabilization and interlaminar decompression: a minimally invasive technique for pedicle screw-based posterior nonfusion stabilization. SAS journal. 2008;2(1):40-42. 
49. Anand N, Baron EM, Kahwaty S. Evidence basis/outcomes in minimally invasive spinal scoliosis surgery. Neurosurgery clinics of North America. 2014;25(2):361-375.

50. Anand N, Baron EM, Khandehroo B. Is circumferential minimally invasive surgery effective in the treatment of moderate adult idiopathic scoliosis? Clinical orthopaedics and related research. 2014;472(6):1762-1768.

51. Anand N, Baron EM, Khandehroo B. Does minimally invasive transsacral fixation provide anterior column support in adult scoliosis? Clinical orthopaedics and related research. 2014;472(6):1769-1775. 52. Anand N, Hamilton JF, Perri B, Miraliakbar H, Goldstein T. Cantilever TLIF with structural allograft and RhBMP2 for correction and maintenance of segmental sagittal lordosis: long-term clinical, radiographic, and functional outcome. Spine. 2006;31(20):E748-753.

53. Schwab F, Lafage V, Patel A, Farcy JP. Sagittal plane considerations and the pelvis in the adult patient. Spine. 2009;34(17):1828-1833.

54. Grubb SA, Lipscomb HJ. Diagnostic findings in painful adult scoliosis. Spine. 1992;17(5):518-527. 55. Cavanilles-Walker J, Ballestero C, Iborra M, Ubierna M, Tomasi S. Adult Spinal Deformity: Sagittal Imbalance. International Journal of Orthopaedics. 2014;1(3).

56. Smith-Petersen MN, Larson CB, Aufranc OE. Osteotomy of the spine for correction of flexion deformity in rheumatoid arthritis. Clinical orthopaedics and related research. 1969;66:6-9.

57. Enercan M, Ozturk C, Kahraman S, Sarier M, Hamzaoglu A, Alanay A. Osteotomies/spinal column resections in adult deformity. European Spine Journal. 2013;22(2):254-264.

58. Hamilton DK, Smith JS, Sansur CA, et al. Rates of new neurological deficit associated with spine surgery based on 108,419 procedures: a report of the scoliosis research society morbidity and mortality committee. Spine. 2011;36(15):1218-1228.

59. Smith JS, Sansur CA, Donaldson WF, 3rd, et al. Short-term morbidity and mortality associated with correction of thoracolumbar fixed sagittal plane deformity: a report from the Scoliosis Research Society Morbidity and Mortality Committee. Spine.

2011;36(12):958-964.

60. Smith JS, Shaffrey CI, Glassman SD, et al. Riskbenefit assessment of surgery for adult scoliosis: an analysis based on patient age. Spine.

2011;36(10):817-824.

61. Smith JS, Shaffrey CI, Sansur CA, et al. Rates of infection after spine surgery based on 108,419 procedures: a report from the Scoliosis Research Society Morbidity and Mortality Committee. Spine.

2011;36(7):556-563.

62. Cho KJ, Suk SI, Park SR, et al. Complications in posterior fusion and instrumentation for degenerative lumbar scoliosis. Spine. 2007;32(20):2232-2237. 63. Daubs MD, Lenke LG, Cheh G, Stobbs G, Bridwell KH. Adult spinal deformity surgery: complications and outcomes in patients over age 60. Spine. 2007;32(20):2238-2244.

\section{Disclosures \& COI}

Neel Anand is a consultant for Medtronic and Theracell, on the scientific advisory board for Globus Medical, owns shares in Medtronics, Globus Medical, Paradigm Spine, Theracell, Atlas Spine, and receives royalties from Globus Medical, Medtronic, and Elsevier. Eli Baron receives royalties from Elsevier and McGraw-Hill. The other authors declare no relevant financial disclosures or conflicts of interest.

\section{Corresponding Author}

Neel Anand, M.D., 444 S San Vicente Blvd. Suite \#800, Los Angeles, CA 90048, neel.anand@cshs.org.

Published 30 June 2017.

This manuscript is generously published free of charge by ISASS, the International Society for the Advancement of Spine Surgery. Copyright @ 2017 ISASS. To see more or order reprints or permissions, see http://ijssurgery.com. 